\title{
PENGGUNAAN AIR PAYAU TERHADAP UJI KUAT TEKAN BATAKO PRESS
}

\author{
Morgan Lamotokana Setiady ${ }^{1}$ Afriadi $^{2}$ \\ Program Studi Teknik Sipil, Fakultas Teknik, Universitas Pattimura, \\ Program Studi Teknik Sipil, Fakultas Teknik, Universitas Muhammadiyah Buton \\ Jl. Jenderal Ahmad Yani No. 9 Maluku \\ E-mail:okan.civil@yahoo.com,afriadicivil@gmail.com
}

\begin{abstract}
Abstrak
Tujuan penenlitian ini adalah untuk mengetahui perbedaan perbandingan kuat tekan Batako Air Kali Biru dengan Batako PDAM Laempanggulu. Untuk menganalisa bagaimana cara mengoptimalkan Batako Kali Biru dengan Batako PDAM Laempanggulu yang sesuaidengan SNI. Dalam penelitian ini, pengujian kuat tekan yang bersusaian dengan Standart kuat tekan mutu batako (SNI-0349-1989) jika ditinjau dari kuat tekan masing-masing benda uji min tingkat mutu IV adalah Batako PDAM Laempanggulu fas 0.8 mempunyai nilai $25.1 \mathrm{~kg} / \mathrm{cm}^{2}$, Batako PDAM Laempanggulu fas 0.9 mempunyai nilai $23.5 \mathrm{~kg} / \mathrm{cm}^{2}$, Batako Air Kali Biru surut fas 0.9 mempunyai nilai $27.52 \mathrm{~kg} / \mathrm{cm}^{2}$ dan Batako Air Kali Biru Pasang 0.8 mempunyai nilai 22,67 kg/ $\mathrm{cm}^{2}$. Sedangkan PDAM Laempanggulu dengan fas 1, Batako Air Kali Biru Surut denganfas 0.8, Batako Air Kali Biru Surut dengan fas 1, Batako Air Kali Biru Pasang dengan fas 0.9 dan Batako Air Kali Biru Pasang dengan fas 1 tidak bersesuaian dengan Standart kuat tekan mutu batako (SNI-0349-1989) karena kuat tekanmasing-masing benda uji min dibawah standar tingkat mutu IV yang mempunyai nilai minimal $21 \mathrm{Kg} / \mathrm{cm}^{2}$.
\end{abstract}

Kata kunci: air payau, Kuat, Batako Press.

\begin{abstract}
The purpose of this study is to know the difference in comparative strength of Batako Air Kali Biru with Batako PDAM Laempanggulu. To analyze how to optimize Batako Kali Biru with Batako PDAM Laempanggulu which is appropriate with SNI. In this study, the compressive strength test in tandem with the compressive strength standard of brick (SNI-0349-1989) when viewed from the compressive strength of each test object min the quality level IV is Batako PDAM Laempanggulu fas 0.8 has a value of $25.1 \mathrm{~kg} / \mathrm{cm} 2$, PDAM Laempanggulu fas 0.9 has a value of $23.5 \mathrm{~kg} / \mathrm{cm} 2$, Batako Air Kali Biru recede fas 0.9 has a value of $27.52 \mathrm{~kg} / \mathrm{cm} 2$ and Batako Air Kali Biru Pasang 0.8 has a value of $22.67 \mathrm{~kg} / \mathrm{cm} 2$. While PDAM Laempanggulu with fas 1, Batako Air Kali Biru Surut denganfas 0.8, Batako Air Kali Biru Surut with fas 1, Batako Air Kali Biru Pasang with fas 0.9 and Batako Air Kali Biru Pasang with fas 1 not in accordance with Standard compressive strength of brick (SNI-0349-1989) because of the strength of each min specimen under the standard quality level IV which has a minimum value of $21 \mathrm{Kg} / \mathrm{cm} 2$.
\end{abstract}

Keywords: brackish water, Strong, Batako Press. 


\section{SANG PENCERAH}

Volume 5, Nomor 1, Februari 2019, Hlm. 26-31

Morgan L. Setiady dan Afriadi: Studi Penggunaan Air Payau ...

\section{Pendahuluan}

Dalam masalah konstruksi, air merupakan bahan utama untuk membuat adonan dan mencampur material yang menjadi bahan utama untuk membuat cor beton, batako, konstruksi bangunan, lapisan dinding, penutup lantai dan sebagainya. Air yang dipakai untuk membuat batako maupun proses percampuran material agregat lainnya harus memenuhi beberapa syarat. Jadi meskipun tidak di gunakan untuk makan dan minum, tapi memilih air untuk membuat bangunan itu tidak boleh sembarangan karena bisa mempengaruhi terhadap kualitas konstruksi dan kerangka bangunan dan beberapa element lain.

SNI atau Standar Nasional Indonesia (SK SNI S-04-1989-F) memberikan syarat standar minimal air yang bisa digunakan untuk membuat bangunan antara lain adalah air tersebut pertama harus bersih dan jernih. Dan selain harus bersih dan jernih, air juga tidak boleh mengandung larutan lumpur terlalu banyak, maksimal 2 gr untuk setiap satu liternya. Air yang kandungan lumpurnya sangat tinggi bisa membuat kualitas bangunan atau konstruksi menjadi tidak sempurna. Kandungan lain yang tidak boleh terdapat pada air adalah lumpur minyak maupun jenis terapan lainnya yang meski tidak bisa dilihat oleh mata atau visual secara langsung.

Untuk larutan garam, ukuran maksimal yang diperbolehkan adalah kurang dari 15 gr setiap satu liternya. Kandungan garam ini jika terlalu tinggi dapat membuat konstruksi bangunan serta material lain yang terbuat dari beton jadi mudah rapuh dan keropos. Karena itu SNI mensyaratkan kandungan ini tidak boleh melebihi ambang batas yang di tentukan yaitu maksimal satu gram per liter. Sedangkan untuk kandungan Clorida atau CL ukuran paling tinggi yang diperbolehkan hanya $1 / 2$ gram saja untuk setiap takaran air satu liter. Air itu juga harus merupakan air tawar, bukan air laut dan air yang diambil dari tempat pengeboran dan penggalian minyak serta kegiatan lain yang sejenis.

Di Kabupaten Buton, khususnya di Desa Banabungi dan sekitarnya sumber mata airnya terasa payau. Mungkin ini di sebabkan karena wilayahnya berada di sekitar pinggir laut. Dahulu masyarakat menggunakan air Kali Biru sebagai pemenuhan kebutuhan seperti makan, minum, mandi dan termasuk di dalamnya sebagai bahan baku konstruksi. Namun seiring perkembangan zaman, kini masyarakat tidak menggunakan air tersebut sebagai bahan pemenuhan kehidupan. PEMDA dalam hal ini telah menggunakan pipa sebagai sarana penyalur air yang dimana air tersebut berasal dari mata air yang tawar dan layak konsumsi seperti PDAM Laempanggulu yang bersumber dari mata air pegunungan. Namun tidak dapat di pungkiri juga ada sebagian masyarakat yang masih menggunakan air tersebut dalam tujuan komersil ataupun untuk keperluan pribadi seperti bahan campuran Beton atau Batako karna di anggapnya hemat biaya. cntohnya adalah pembangunan tempat Wisata Kali Biru, Pasarwajo Kabupaten Buton serta sebagian rumah penduduk yang berada di sekitar Kali Biru. Berdasarkan uraian di atas, fokus penelitian ini adalah bagaimanakah Perbandingan Kuat Tekan batako Air Kali Biru Dengan Batako Air PDAM Laempanggulu sebagai pembanding yang bersesuaian dengan SNI?

Tujuan penelitian ini adalah untuk mengetahui Perbandingan Kuat Tekan batako Air Kali Biru Dengan Batako Air PDAM Laempanggulu sebagai pembanding yang bersesuaian dengan SNI.

\section{Metode Penelitian}

\section{SNI-3-0349-1989}

Syarat bata beton harus memenuhi syarat-syarat fisis. Perhatikan table berikut. 


\section{SANG PENCERAH}

Volume 5, Nomor 1, Februari 2019, Hlm. 26-31

Morgan L. Setiady dan Afriadi: Studi Penggunaan Air Payau ...

Tabel 1 Syarat-Syarat Fisis Bata Beton

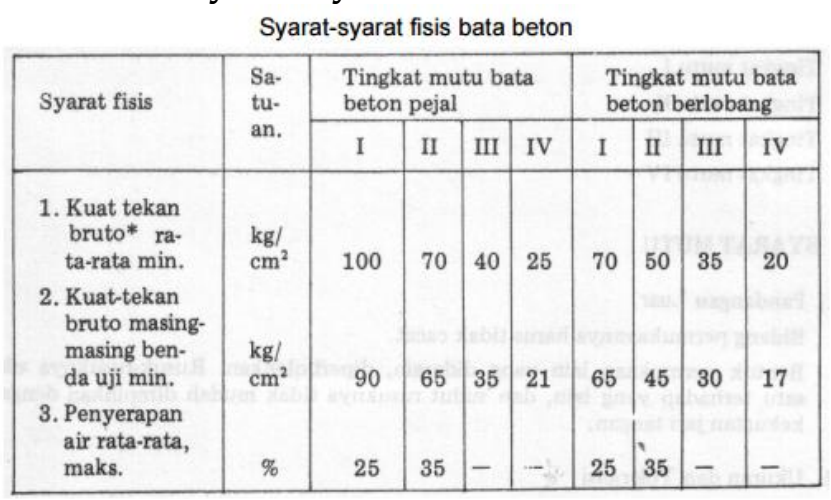

\section{Lokasi dan Bahan}

Sampel air pada penelitian ini, diambil di Kabupaten Buton Kecamatan Pasarwajo, Desa Banabungi yang dikenal sebagai Kali Biru dan yang digunakan sebagai pembanding adalah air PDAM Laempanggulu.

\section{Benda Uji}

\section{Bahan}

Bahan utama yang akan digunakan dalam penelitian ini adalalah semen portland, air Kali Biru, air PDAM Laempanggulu dan agregat pasir. Pasir yang akan di gunakan adalah pasir laut Desa Wasaga Kecamatan Pasarwajo Kabupaten Buton.

\section{Peralatan}

Peralatan yang digunakan adalah Cetakan benda uji berbentuk kubus yang berukuran $30 \mathrm{~cm} \times 15 \mathrm{~cm} \times 7 \mathrm{~cm}$. Mixer Concrete, ayakan pasir, timbangan dengan ketelitian 0,1 gram, Alat pelapis (Capping) dan balok kayu sesuai dengan ukuran cetakan, peralatan tambahan ( ember, sekop, sendok, meter, perata dan talam) dan Compression Machine untuk pengujian kuat tekan beton.

\section{Komposisi}

Benda uji dibuat dengan komposisi 1:3:3. Standart sampel pada pembuatan batako pada penelitian ini adalah 18 buah. Penelitian ini penggunaan sampel pada penggunanaan air adalah 2 sampel air dengan penggunaan 3 faktor air semen yang meliputi 0,$8 ; 0,9$; dan 1 . Dimana tiap sampelnya dibuat 2 buah. Benda uji dibuat dengan komposisi campuran yang sama yaitu $1: 3: 3$ dimana $1 \mathrm{~kg}$ semen, $3 \mathrm{~kg}$ pasir serta $3 \mathrm{~kg}$ kerikil/spilit dengan penggunaan faktor air semen adalah 0,8 0,9 dan 1 .

\section{Metode Pengujian}

Pada pengujian kuat tekan batako alat yang akan dipergunakan ialah Compression machine test, batako yang telah di buat dan di keringkan selama waktu yang telah di tentukan kemudian batako air Kali biru dan batako PDAM Laempanggulu di uji kuat tekan masing- masing dan dihitung menggunakan rumus untuk mengetahui hasilnya. Berikut adalah gambar mesin kuat tekan Machine Test.

\section{Metode Analisis}

\section{Kuat Tekan Beton}

Kuat tekan beton diukur dengan cara memberikan gaya aksial $(\mathrm{P})$ yang terdistribusi pada batang penekan compressive strength machine. Gaya tersebut diterima oleh luas penampang benda uji silinder, sehingga terjadi tegangan ( $\left.\mathrm{fc}^{\prime}\right)$ yang merata keseluruh penampang (A). Dengan rumus :

$f c^{\prime}=\frac{P}{A}(M P a)$

$$
\begin{aligned}
& \text { Keterangan: } \\
& \mathrm{fc}^{\prime}=\text { Kuat tekan beton }(\mathrm{MPa}) \\
& \mathrm{P}=\text { Beban aksial }(\mathrm{N}) \\
& \mathrm{A}=\text { Luas penampang benda uji }\left(\mathrm{mm}^{2}\right)
\end{aligned}
$$

\section{Pembahasan}

\section{Perbandingan Kuat Tekan Batako Air PDAM Laempanggulu dengan Kali Biru}

Berdasarkan tabel persyaratan minimal penggunaan batako sebagai dinding menurut SNI-3-0349-1989, jika dilihat dari kuat tekan masing-masing benda uji min, ditinjau dari nilai kuat tekan maka didapatkan, Untuk 


\section{SANG PENCERAH}

Volume 5, Nomor 1, Februari 2019, Hlm. 26-31

Morgan L. Setiady dan Afriadi: Studi Penggunaan Air Payau ...

batako air PDAM Laempanggulu Laempanggulu dengan fas 0,8 yang mempunyai nilai kuat tekan sebesar 25.1 $\mathrm{kg} / \mathrm{cm}^{2}$ masuk dalam kategori Tingkat mutu IV maka artinya batako tersebut layak pakai. Untuk batako air PDAM Laempanggulu Laempanggulu dengan fas 0,9 yang mempunyai nilai kuat tekan sebesar 23.5 $\mathrm{kg} / \mathrm{cm}^{2}$ masuk dalam kategori Tingkat mutu IV maka artinya batako tersebut layak pakai.

Untuk batako air PDAM Laempanggulu dengan fas 1 yang mempunyai nilai kuat tekan sebesar 14.56 $\mathrm{kg} / \mathrm{cm}^{2}$ tidak masuk dalam kategori Tingkat mutu IV karena nilai kuat tekan minimal yang disyaratkan tidak sesuai maka artinya batako tersebut tidak layak pakai. Untuk Batako Air Kali Biru Surut dengan fas 0,8 yang mempunyai nilai kuat tekan sebesar $18.64 \mathrm{~kg} / \mathrm{cm}^{2}$ tidak masuk dalam kategori Tingkat mutu IV karena nilai kuat tekan minimal yang disyaratkan tidak sesuai maka artinya batako tersebut tidak layak pakai. Untuk Batako Air Kali Biru Surut dengan fas 0,9 yang mempunyai nilai kuat tekan sebesar $27.52 \mathrm{~kg} / \mathrm{cm}^{2}$ masuk dalam kategori Tingkat mutu IV maka artinya batako tersebut layak pakai. Untuk batako air Kali Biru Surut dengan fas 1 yang mempunyai nilai kuat tekan sebesar $14,61 \mathrm{~kg} / \mathrm{cm}^{2}$ tidak masuk dalam kategori Tingkat mutu IV karena nilai kuat tekan minimal yang disyaratkan tidak sesuai maka artinya batako tersebut tidak layak pakai.

Untuk batako air Kali Biru Pasang dengan fas 0,8 yang mempunyai nilai kuat tekan sebesar $22,67 \mathrm{~kg} / \mathrm{cm}^{2}$ maka batako tersebut layak pakai. Untuk Batako Air Kali Biru Pasang dengan fas 0,9 yang mempunyai nilai kuat tekan sebesar $12,96 \mathrm{~kg} / \mathrm{cm}^{2}$ tidak masuk dalam kategori Tingkat mutu IV karena nilai kuat tekan minimal yang disyaratkan tidak sesuai maka artinya batako tersebut tidak layak pakai. Untuk Batako Air Kali Biru Pasang dengan fas 1 yang mempunyai nilai kuat tekan sebesar 12,14 $\mathrm{kg} / \mathrm{cm}^{2}$ tidak masuk dalam kategori Tingkat mutu IV karena nilai kuat tekan minimal yang disyaratkan tidak sesuai maka artinya batako tersebut tidak layak pakai.

Ditinjau dari nilai kuat tekan batako pada perbandingan kuat tekan batako air PDAM Laempanggulu dan batako air Kali Biru didapatkan hasil sebagai berikut.

1. Batako press dengan menggunakan air PDAM Laempanggulu adalah sebagai berikut:

a. Fas 0,8 mempunyai nilai kuat tekan sebesar $25.1 \mathrm{~kg} / \mathrm{cm}^{2}$.

b. Fas 0,9 mempunyai nilai kuat tekan sebesar $23.5 \mathrm{~kg} / \mathrm{cm}^{2}$.

c. Fas 1 mempunyai nilai kuat tekan sebesar $14.56 \mathrm{~kg} / \mathrm{cm}^{2}$.

2. Batako press dengan menggunakan air Kali Biru Surutadalah sebagai berikut :

a. Fas 0,8 mempunyai nilai kuat tekan sebesar $18.64 \mathrm{~kg} / \mathrm{cm}^{2}$.

b. Fas 0,9 mempunyai nilai kuat tekan sebesar $27.52 \mathrm{~kg} / \mathrm{cm}^{2}$.

c. Fas 1 mempunyai nilai kuat tekan sebesar $14,61 \mathrm{~kg} / \mathrm{cm}^{2}$.

3. Batako press dengan menggunakan air Kali Biru Pasang adalah sebagai berikut :

a. Fas 0,8 mempunyai nilai kuat tekan sebesar $22,67 \mathrm{~kg} / \mathrm{cm}^{2}$.

b. Fas 0,9 mempunyai nilai kuat tekan sebesar $12,96 \mathrm{~kg} / \mathrm{cm}^{2}$.

c. Fas 0,9 mempunyai nilai kuat tekan sebesar $12,14 \mathrm{~kg} / \mathrm{cm}^{2}$.

Jika di tinjau dari kelayakan batako yang bersesuai dengan SNI-0349-1989, batako pada perbandingan kuat tekan batako air PDAM Laempanggulu dan batako air Kali Biru didapatkan kesimpulan sebagai berikut:

1. Batakopress dengan menggunakan air PDAM Laempanggulu Laempanggulu adalah sebagai berikut :

a. Fas 0,8 yang mempunyai nilai kuat tekan sebesar $25.1 \mathrm{~kg} / \mathrm{cm}^{2}$ masuk dalam kategori Tingkat mutu IV maka artinya batako tersebut layak pakai.

b. Fas 0,9 yang mempunyai nilai kuat tekan sebesar $23.5 \mathrm{~kg} / \mathrm{cm}^{2}$ masuk 


\section{SANG PENCERAH}

Volume 5, Nomor 1, Februari 2019, Hlm. 26-31

Morgan L. Setiady dan Afriadi: Studi Penggunaan Air Payau ...

dalam kategori Tingkat mutu IV maka artinya batako tersebut layak pakai.

c. Fas 1 yang mempunyai nilai kuat tekan sebesar $14.56 \mathrm{~kg} / \mathrm{cm}^{2}$ tidak masuk dalam kategori Tingkat mutu IV karena nilai kuat tekan minimal yang disyaratkan tidak sesuai maka artinya batako tersebut tidak layak pakai.

2. Batako press dengan menggunakan air Kali Biru Surut adalah sebagai berikut :

a. Fas 0,8 yang mempunyai nilai kuat tekan sebesar $18.64 \mathrm{~kg} / \mathrm{cm}^{2}$ tidak masuk dalam kategori Tingkat mutu IV karena nilai kuat tekan minimal yang disyaratkan tidak sesuai maka artinya batako tersebut tidak layak pakai.

b. Fas 0,9 yang mempunyai nilai kuat tekan sebesar $27.52 \mathrm{~kg} / \mathrm{cm}^{2}$ masuk dalam kategori Tingkat mutu IV maka artinya batako tersebut layak pakai.

c. Fas 1 yang mempunyai nilai kuat tekan sebesar $14,61 \mathrm{~kg} / \mathrm{cm}^{2}$ tidak masuk dalam kategori Tingkat mutu IV karena nilai kuat tekan minimal yang disyaratkan tidak sesuai maka artinya batako tersebut tidak layak pakai.

3. Batako press air Kali Biru Pasang adalah sebagai berikut:

a. Fas 0,8 yang mempunyai nilai kuat tekan sebesar $22,67 \mathrm{~kg} / \mathrm{cm}^{2}$ maka batako tersebut layak pakai.

b. Fas 0,9 yang mempunyai nilai kuat tekan sebesar $12,96 \mathrm{~kg} / \mathrm{cm}^{2}$ tidak masuk dalam kategori Tingkat mutu IV karena nilai kuat tekan minimal yang disyaratkan tidak sesuai maka artinya batako tersebut tidak layak pakai.

c. Fas 0,9 yang mempunyai nilai kuat tekan sebesar $12,14 \mathrm{~kg} / \mathrm{cm}^{2}$ tidak masuk dalam kategori Tingkat mutu IV karena nilai kuat tekan minimal yang disyaratkan tidak sesuai maka

\section{Simpulan}

Simpulan penelitian ini bahwa pengujian kuat tekan yang bersusaian dengan Standart kuat tekan mutu batako (SNI-0349-1989) jika ditinjau dari kuat tekan masing-masing benda uji min tingkat mutu IV adalah Batako PDAM Laempanggulu fas 0.8 mempunyai nilai $25.1 \mathrm{~kg} / \mathrm{cm}^{2}$, Batako PDAM Laempanggulu fas 0.9 mempunyai nilai $23.5 \mathrm{~kg} / \mathrm{cm}^{2}$, Batako Air Kali Biru surut fas 0.9 mempunyai nilai $27.52 \mathrm{~kg} / \mathrm{cm}^{2}$ dan Batako Air Kali Biru Pasang 0.8 mempunyai nilai 22,67 kg/ $\mathrm{cm}^{2}$. Sedangkan PDAM Laempanggulu dengan fas 1, Batako Air Kali Biru Surut denganfas 0.8, Batako Air Kali Biru Surut dengan fas 1, Batako Air Kali Biru Pasang dengan fas 0.9 dan Batako Air Kali Biru Pasang dengan fas 1 tidak bersesuaian dengan Standart kuat tekan mutu batako (SNI-0349-1989) karena kuat tekanmasingmasing benda uji min dibawah standar tingkat mutu IV yang mempunyai nilai minimal $21 \mathrm{Kg} / \mathrm{cm}^{2}$.

\section{Daftar Pustaka}

Afriadi. 2016. Perbandingan Kuat Tekan Batako Paving Block Menggunakan Agregat Pasir Dan Batu Kapur. Tugas Akhir, Jurusan Teknik Sipil, Fakultas Teknik, Universitas Muhammadiyah Buton.

Antoni dan Paul Nugraha. 2007.Teknologi Beton. Yogyakarta: Penerbit CV Andi Offset.

Departemen Pekerjaan Umum. Badan Penelitian dan Pengembangan PU, PedomanBeton 1989. SKBI.1.4.53.1989.

Departemen Pekerjaan Umum, 1989. Bata Beton Untuk Pasangan Dinding SNI 03-0349-1989. Badan Standarisasi Nasional, Jakarta.

Departemen Pekerjaan Umum, 1993. Tata Cara Pembuatan Rencana Campuran Beton Normal 


\section{SANG PENCERAH}

Volume 5, Nomor 1, Februari 2019, Hlm. 26-31

Morgan L. Setiady dan Afriadi: Studi Penggunaan Air Payau ...

SNI 03-2834-1993. Badan Standarisasi Nasional, Jakarta.

Departemen Pekerjaan Umum. Badan Penelitian dan Pengembangan PU, Pedoman Beton 1989. SKBI.1.4.53.1989.

Iptekda-Lipi, 2004, Pembuatan Batako dan Paving Block secara Maksimal.

Irzal

Agus.

http://ejournal.narotama.ac.id/files/faktor_air semen.pdf. PENGARUH VARIASI FAKTOR AIR SEMEN DAN TEMPERATUR TERHADAP KUAT TEKAN BETON. Fakultas Teknik, Universitas Dayanu Iksanudidin Bau- Bau.

Mulyono, T. 2005. Teknologi Beton. Yogyakarta: Andi.

Rustam, 2015. Pengujian Agregat Kasar Dan Agregat Halus Batauga Dengan Air Payau Sebagai Bahan Agregat Campuran Beton, Tugas Akhir, Jurusan Teknik Sipil, Fakultas Teknik, Universitas Muhammadiyah Buton.

Sarlindawati, S. 2005. Pemanfaatan Limbah Batu Bata sebagai Bahan Batako Alternatif. Tugas Akhir, Jurusan Teknik Sipil, Fakultas Teknik, Universitas Muhammadiyah Surakarta.

Tjokrodimuljo, K. 1996. Teknologi Beton. Biro Penerbit Keluarga Mahasiswa Teknik Sipil Universitas Gadjah Mada, Yogyakarta. 